\title{
Natural products extract effect on bone integration around orthodontic micro-implant: An experimental study
}

\begin{tabular}{cc}
\hline Mustafa Muath Hamed Al-Sultan* & Ali Rajih Al-Khatib* \\
\hline Abstract &
\end{tabular}

Background and objective: Bone integration around orthodontic implant is a matter of concern for their stability. This study was conducted to estimate calcium and phosphorous level in after insertion of orthodontic implant.

Methods: Twenty five white mature male rabbits, classified into 5 groups: one control and four experimental, with five rabbits for each group were used. Fifty orthodontic implants were used, 2 micro-implant for each tibia. Four different natural products extract were used in this study that included Curcumin $15 \mathrm{mg} / \mathrm{kg}$, Nigella Sativa oil $0.25 \mathrm{ml} / \mathrm{kg}$, Cissus Quadrangularis $500 \mathrm{mg} / \mathrm{kg}$ and Virgin Coconut oil $1 \mathrm{ml} / \mathrm{kg}$. Each product was given to certain experimental group started from the day of implant insertion for four weeks healing period. The biochemistry evaluation was conducted involving calcium and phosphorus level in serum.

Results: Significant difference in serum calcium levels were detected between Curcumin, Nigella Sativa oil from side and control group on the other side.

Conclusion: Systemic Curcumin and Nigella sativa oil may be used for possibly enhancing bone response around orthodontic implant as reflected by lower serum calcium level as compared to control group.

Keywords: Calcium and phosphorus, Natural products, Orthodontic implant.

\section{Introduction}

Many efforts have been spent by the researchers and clinicians to use the implant as anchorage unit in orthodontics. ${ }^{1}$ Linkow $^{2}$ in his case report that is considered as the first published work in this field, used mandibular blade-vent implant with class II elastic to retract maxillary incisors. After that, in the last few years, anchorage reinforcement becomes possible and wide spread with mini-implants which proved to provide reliable anchorage., ${ }^{3,4}$ For orthodontic implants to be successful, several factors should be taken in consideration such as bone quality and bone quantity. ${ }^{5,6}$ The bone and its surrounding structures is considered as one of the most important factors that may affect the implant success rate. Bone healing is a local process that has an effect on systemic mineral homeostasis. ${ }^{7}$ The major component and essential ingredient of human bones is a mineral form of calcium and phosphorus called hydroxyapatite $\left[\mathrm{Ca}_{10}\left(\mathrm{PO}_{4}\right)_{6}(\mathrm{OH})_{2}\right]$. The calcium and phosphorus components of these crystals are derived from the blood, where the calcium level in blood would be lowered during bone formation but phosphorus elevated this reflect that their percentages are inversely proportioned. $^{8}$ For that reason, sufficient calcium and phosphorus is necessary to ensure the proper balance of essential minerals in order to promote re-mineralization of bones. ${ }^{9}$ A number of natural products were used since before for controlling bone metabolism in an attempt to promote anabolic effect or limiting/ suppressing the catabolism. Also, Vitamin $\mathrm{E}^{10}$ added to natural herbal products such as Eurycomalongifola, Labisiapumila that mainly extracts from the whole plant or specific parts of the

*Department of orthodontic, college of dentistry, university of Mosul, Mosul, Iraq. 
plants, such as the fruit, leaves, or roots. ${ }^{11}$ According to our best knowledge, limited information is available regarding the effects of the natural products on calcium and phosphorous level after insertion of orthodontic or even surgical implants. Thus, the purpose of this study was to estimate the effect of Curcumin, Nigella Sativa, Cissus Quadrangularis and Virgin Coconut oil extracts on calcium and phosphorous level using biochemical evaluation methods.

\section{Methods}

In this study 50 sterile orthodontic micro implants were used with diameter of $1.3 \mathrm{~mm}$ and length of $5 \mathrm{~mm}$ (Dentos, AbsoAnchor, SH1312-5/ tapered type, Dentos Inc. 1-5, Galsan-Dong, Dalseo-Gu, Daegu, Korea 704-900). Twenty five healthy mature male rabbits weight 2-2.25 kilogram, 7-10 months-old, were used after receiving the bioethical approval of animal care from the University of Mosul in 24/11/2013. These rabbits were divided into 5 groups, each group 5 rabbits: First group was control that subjected to implant insertion but not given natural products. The remaining four groups were experimental that were subjected to implantation and given natural products. The implantation procedures

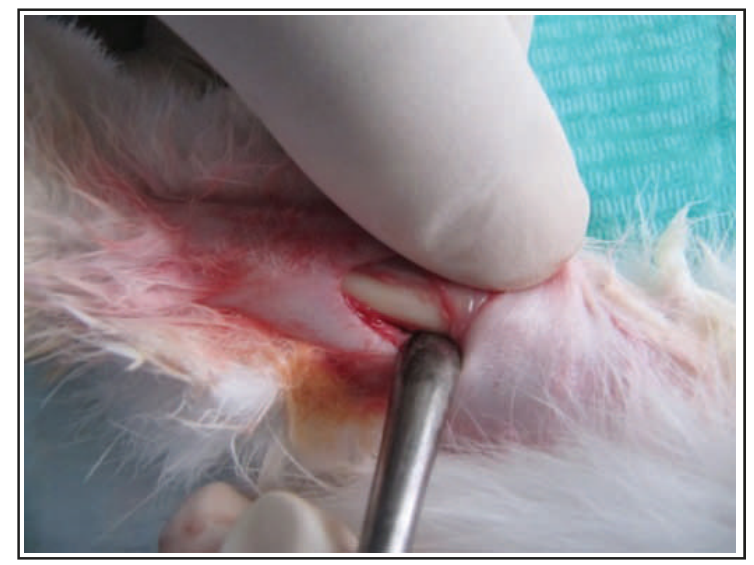

Figure 1: Soft tissue incision and bone exposure. were common to all animals and consisted of placement of two implants $10 \mathrm{~mm}$ between each other in medial surface of the right tibia of each animal. All operations were performed under sterile conditions in a certain operating room, prepared for this purpose. Immediately before the surgery, the animals were anesthetized with intramuscular injection of $0.2 \mathrm{ml} / \mathrm{kg}$ body weight Ketamine 10\% (KEPRO B.V. Maagdenburgstraat 38-7421 ZE DeventerHolland) and $0.15 \mathrm{ml} / \mathrm{kg} \mathrm{b.w.} \mathrm{Xylazine} 2 \%$ (alfasan.Woerden-Holland). ${ }^{12}$ The surgical area anaesthetized with $1 \mathrm{ml}$ local anesthetic solution $2 \%$ Xylocain. The hair on the medial surface of the right leg clipped and the skin wiped thoroughly with Betadine solution (10\% povidine iodine topical solution, purdue products L.P., Stamford) with sterile surgical gauze. An incision of approximately $20 \mathrm{~mm}$ in length down parallel to longitudinal axis of the tibia, in the medial aspect was conducted. The skin, fascia and muscles were dissected then the periosteum was stripped and elevated denuding the bone in medial aspect of tibia (Figure 1). Two implantation holes about $10 \mathrm{~mm}$ apart were drilled with a $1 \mathrm{~mm}$ rounded drill under profuse sterile saline-solution irrigation and at low rotary speed (Figure 2).

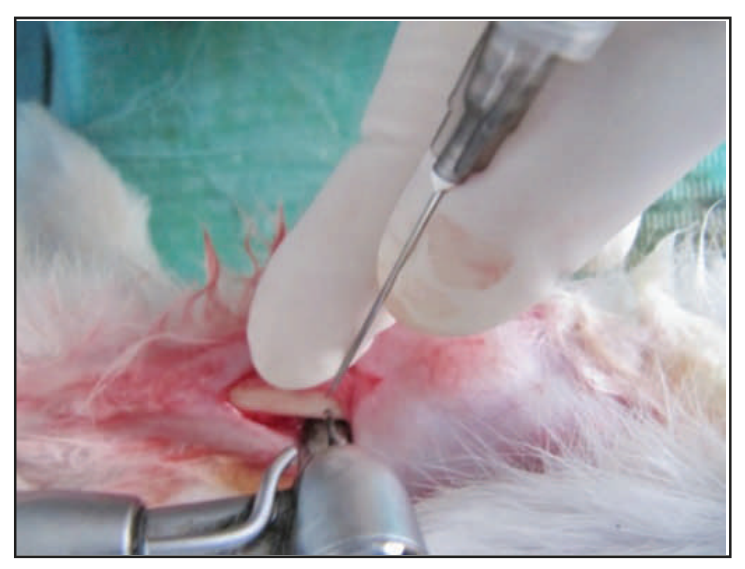

Figure 2: Implant hole preparation in tibia. 
http://dx.doi.org/10.15218/zjms.2016.0012

The implants were threaded in the tibia with a manual driver with the full length of the serrated part inside the bone, till reaching the neck of the implant head collar (Figure 3,4) keeping their longitudinal axes parallel to each other and perpendicular to the external cortical tibia. The periostium and deep fascia were repositioned in their original place and the skin was sutured (Figure 5) with black silk suture (3-0). The rabbit was then placed in postoperative recovery. Once fully recovered, the rabbits were placed in their respective holding areas. Then the natural products loaded for experimental groups as follows:

1. Curcumin: For first group one capsule of curcumin "CurcuVET-SA150/ Curcumin complexes with phosphatidylcholine for superior bioavailability/ pure ingredient" (Throne Research, Inc. p.o. Box 25 Dover, ID 83825 USA) which contain $10 \mathrm{mg} /$ kilogram of curcumin was given for each rabbit by dissolution of capsule content in distilled water and given

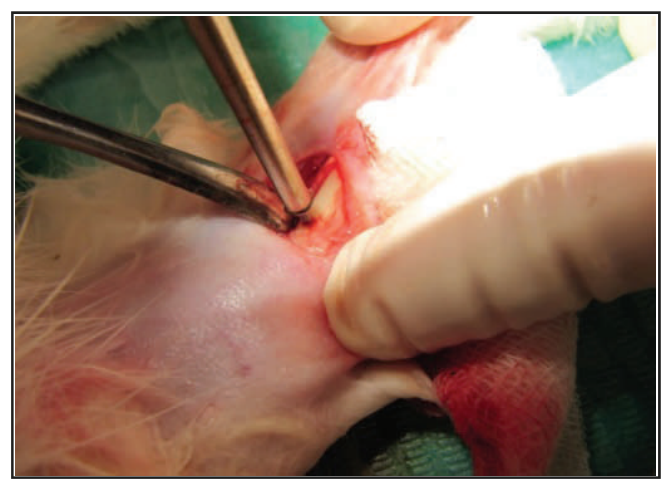

Figure 3: Screw insertion in tibia.

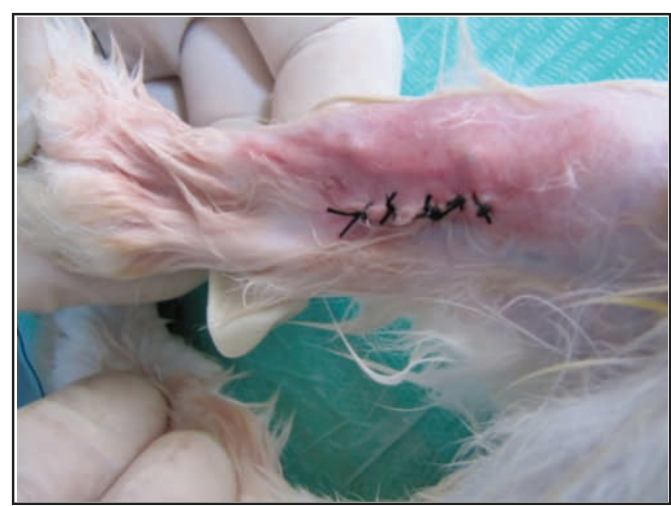

Figure 5: Skin suturing. directly through oral gavages". The dose was selected for this study taken with regard to different studies worked on bone metabolism using curcumin which range from 10-10000 mg/ Kg BW. ${ }^{13-15}$

2. Nigella Sativa oil (NSO): For this group, "Pure cold pressed 100ml Black Seed oil from Nigella Sativa seeds $0.25 \mathrm{ml} /$ Kilogram (kg) body weight (b.w.)" (The Blessed Seed oil/ Black seed oil specialist/ Beverley, United Kingdom), given freshly through oral gavages. Nigella Sativa oil dose selection was based on safety dose level. ${ }^{16,17}$

3. Cissus Quadrangularis (CQ): For this group, $500 \mathrm{mg} /$ kilogram b.w. "100\% pure organic Cissus Quadrangularis extract by Keter Wellness/ under strict of good manufacturing practice (GMP) guidelines/ United State of America" (capsule weight $1 \mathrm{gm}$ ) by dissolution of capsule content in distilled water. The dose was selected in reference to other studies which range from $500-750 \mathrm{mg} / \mathrm{kg} .{ }^{18,19}$

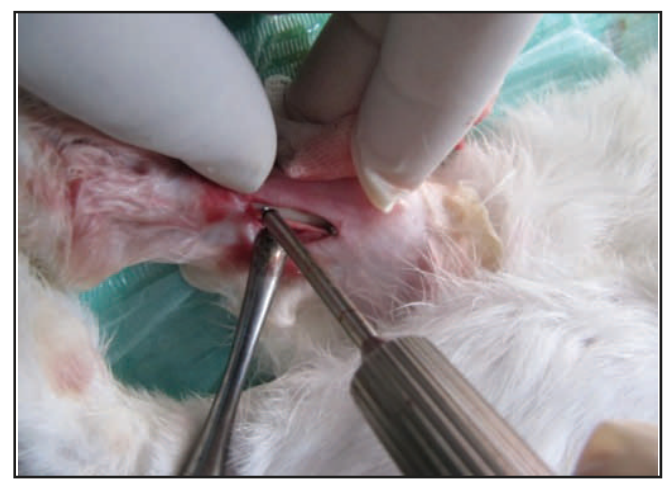

Figure 4: Two implants inserted with $10 \mathrm{~mm}$ distance in between. 
4. Virgin Coconut oil (VCO): For this group, $1 \mathrm{ml} / \mathrm{kg}$ b.w. Organic Pure Raw (Live superfoods, 20739, High Desert Court Bend, Oregon 97701). The dose selection was based on previous studies which range from 1-2 ml/ kg. ${ }^{20,21}$

All of these natural products were given as a loading dose for 4 weeks, started from the day of implant insertion. After 4 weeks healing period all of the rabbits were sacrificed in the same specially prepared theater under same circumstances. The rabbits were fasted overnight till morning for 12 hours. The sacrificing process was conducted by slaughtering with sterile large surgical blade to collect the blood sample for serum isolation. Once slaughtering started few blood drops were left down, not used to avoid hemolysis of blood sample, then the remaining gusher blood was collected in sterile glass test. After complete collection of blood in the serum separator tubes, serum collection achieved by leaving the blood inside the separating tubes for 30 minutes to allow for clotting to be achieved at room temperature. After centrifuging the blood inside the test tubes with centrifuge (EBA-20/ HettichZENTRIFUGEN/ China) at a rate of 3000 turn/ 10 minutes. The serum drawn from the test tube with micro-pipette the extracted serum then putted in Eppendorf tubes which held in Eppendorf rack and putted in refrigerator at -20 co for serum preservation till the biochemistry test which did after two weeks. Prior to assay, the frozen sample brought to room temperature slowly and mixed gently. The biochemical evaluation involve measuring serum calcium, which was determined in an ordinary method using atomic absorption spectrophotometer (Spectrophotometer-Germany) milligram/ deciliter $(\mathrm{mg} / \mathrm{dl})$ level in serum. Serum phosphorus was determined using auto analyzer (Cobas Integra 400 plus/ Rouch-Germany) mg/dl level in serum. The method of analysis is shown in Figure 6.

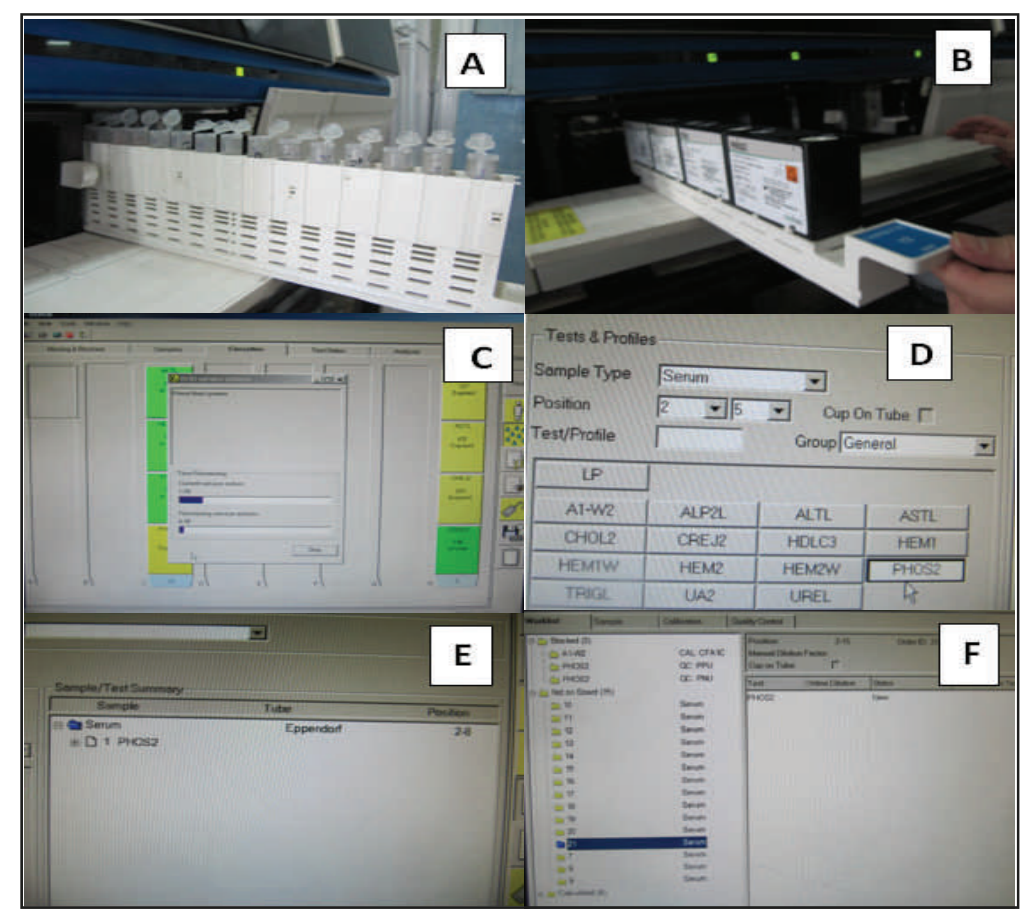

Figure 6: Auto analyzer for serum biomarker analysis: (A) Eppendrofs with serum loaded in the machine. (B) Loading the container specific for the biomarker to be measured. (C) Switch on the analyzer software. (D) Selection of the marker for analysis. (E) Selecting serum specimen in sample/ test summary. (F) Click the icon of each marked specimen to know their serum concentration. 


\section{Results}

The descriptive statistics for the study groups are presented in Table 1. A one-way analysis of variance (ANOVA) was conducted to compare the effect of the study materials on calcium and phosphorus level in the blood. There was a significant effect of these products on calcium level in the blood and there were no statistically significant differences between group means for phosphorus groups (Table 2).

Table 1: The descriptive statistics including means and standard deviation of serum calcium and phosphorus for the study groups.

\begin{tabular}{lll}
\hline Study groups & Mean & Std. Deviation \\
\hline Control calcium & 14.09 & 1.07 \\
Curcumin calcium & 12.06 & 0.66 \\
Cissus Quadrangularis calcium & 12.84 & 0.69 \\
Nigella Sativa calcium & 11.86 & 0.38 \\
Vigin Coconut oil calcium & 13.28 & 0.48 \\
Control phosphorus & 4.63 & 0.85 \\
Curcumin phosphorus & 6.18 & 1.62 \\
Cissus Quadrangularis phosphorus & 5.07 & 1.09 \\
Nigella Sativa phosphorus & 4.83 & 1.05 \\
Virgin Coconut phosphorus & 5.20 & 1.37 \\
\hline
\end{tabular}

Table 2: Represents the one way analysis of variance of calcium and phosphorus for the study groups.

\begin{tabular}{lllllll}
\hline & & $\begin{array}{l}\text { Sum of } \\
\text { Squares }\end{array}$ & df & Mean Square & F & P value \\
\hline Calcium groups & Between Groups & 16.721 & 4 & 4.180 & 8.543 & 0.001 \\
& Within Groups & 9.786 & 20 & .489 & & \\
& Total & 26.507 & 24 & & & \\
Phosphorous & Between Groups & 7.168 & 4 & 1.792 & 1.184 & 0.348 \\
groups & Within Groups & 30.263 & 20 & 1.513 & & \\
& Total & 37.431 & 24 & & & \\
\hline
\end{tabular}


Scheffe's test was used to make post oil differed significantly at $P<0.05$. hoc comparisons among calcium groups (Table 3). This test showed that the mean value of Curcumin and Nigella Sativa However, the mean value of control group was not significantly different from the other groups.

Table 3: Scheffe's multiple comparisons for the calcium analysis.

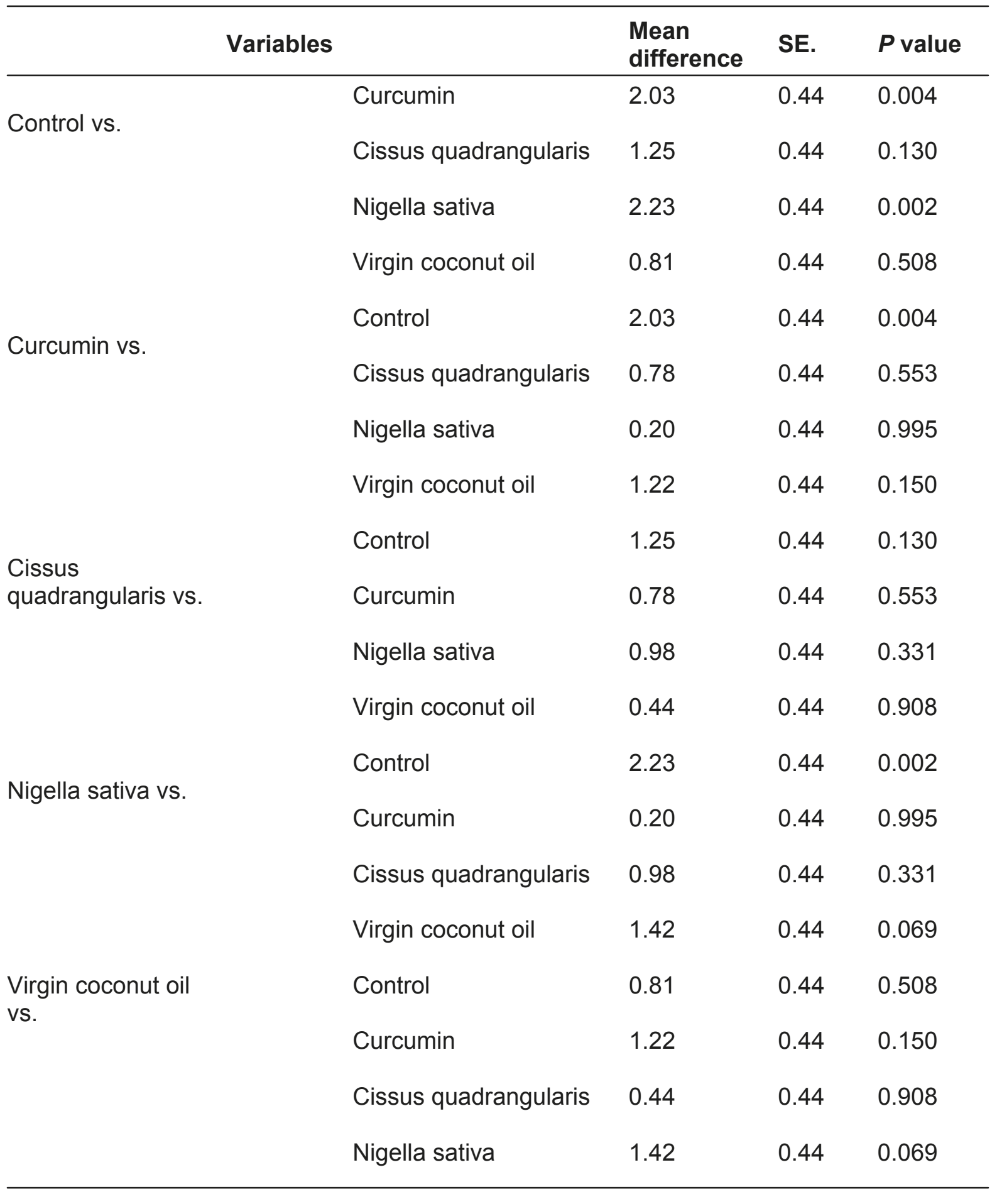




\section{Discussion}

Bone integration or optimizing bone formation around orthodontic implant is a matter of concern. Identification of a substance with a positive effect on bone integration would possibly improve implant stability and could have a significant clinical relevance on implant failure. Recently, many investigations have been carried out on factors which may be able to increase the speed and quantity of bone formation around dental implants. ${ }^{22-25}$ This study tried to use four types of natural products to test their possible effect on bone integration around orthodontic implant represented by serum biochemistry evaluation. The study condition is differing from previous studies, as there was traumatic injury, inflammation and bone response pathologic remodeling. ${ }^{26,27}$ Significant differences for serum calcium on comparing Curcumin and NSO groups with control one were detected with lower serum calcium level for experimental groups. VCO and CQ groups also showed low serum calcium level in comparison with control group although statistically not significant referring to mean. These results cab probably be explained by the natural products activity at osseous level as mentioned above. These may be the result of increased calcium intake by the bone during formation and remodeling process. This result could come in agreement with the result achieved by Komnenou et al, ${ }^{28}$ who conducted a study on 83 dogs, with closed long bone diaphyseal fractures treated surgically. The serum calcium and phosphate were evaluated at day of admission, 10, 20, 30 then 2 months then at 5 months. Their study results showed that Serum Phosphorus and Calcium changes followed a proportional and inverse pattern. This inverse relation between serum calcium and serum phosphorus was further documented by Kini and Nandeesh, ${ }^{29}$ which be under the control of parathyroid hormone that regulates serum calcium and phosphorus concentrations through its receptor-mediated, combined actions on bone. In that on continues release of parathyroid hormone lead to bone resorption and opposite to it, bone formation occur with intermittent release of parathyroid hormone. Animal studies have demonstrated the importance of phosphorus, in conjunction with calcium, for bone development. ${ }^{30}$ Their results showed that calcium and phosphorus are co-dependent, and that both minerals are critical to support soft tissue and bone growth. ${ }^{29}$ In a study by Cohen et al on bone graft, stated that no evidence can be withdrawn from data for local preferential transfer of calcium to callus from grafts or bone store adjacent to the grafted area. ${ }^{31}$ On contrary, all of the data may be used to support the hypothesis that calcium in callus or newly formed bone is completely from serum. So result in lower blood serum calcium level. At less than two weeks the blood contained no activity, and at more than three weeks of bone healing the specific activity of blood had dropped below the level at which the most active bone formation could possibly have been formed. The present study result come in accordance with Cohen et $\mathrm{al}^{31}$ study and also agreed with Deka et al in 1994 which showed a lower serum calcium level accompanying bone fracture healing using Cissus Quadrangularis. ${ }^{32}$ The present study result also agreed with Abdel-Sater and Mansour study in 2013, which showed statistically lowered serum calcium level while serum phosphorus showing non -significant elevation. ${ }^{33}$ The present study results are also in agreement with Yang et $\mathrm{al}^{34}$ whom showed that the Curcumin have the ability to improve the bone microarchitecture and bone mineral density in amyloid precursor protein/presenilin 1 (APP/PSI) transgenic mice. Moreover, Moon et al showed that Curcumin could stop osteoclastogenesis through suppression of RANKL activity completely in an in vitro study. ${ }^{35}$ Further an in vivo studies conducted by Hussan et al and Cho et al showed that using Curcumin could limit bone loss, improve remodeling 
and improve bone strength in osteoporosis animal models. ${ }^{36,37}$ These previous in vitro and in vivo studies of Curcumin activity at osseous level could possibly be used to explain their significantly higher value than our control group.

\section{Conclusion}

The natural products extract, Curcumin and Nigella sativa oil may be systemically used for possibly enhancing bone response around orthodontic implant as reflected by lower serum calcium level as compared to control group.

\section{Conflicts of interest}

The authors report no conflicts of interest.

\section{References}

1. Mute BR, Peter KP, Daokar S. Orthodontics Implants in Orthodontics- A New Paradigm. IOSR Journal of Dental and Medical Sciences 2013; 10(5): 78-84.

2. Linkow LI. The endosseous blade implant and its use in orthodontics. Int J Orthod 1969; I 8:149-54.

3. Yao CC, Lai EH, Chang JZ. Comparison of treatment outcomes between skeletal anchorage and extraoral anchorage in adults with maxillary dentoalveolar protrusion. Am J Orthod DentofacialOrthop 2008; 134(5): 615-24.

4. Upadhyay M, Yadav S, Patil S. Mini-implant anchorage for en-masse retraction of maxillary anterior teeth: a clinical cephalometric study. Am J Orthod Dentofacial Orthop 2008; 134(6): 803-10.

5. Zheng L, Tang T, Deng F, Zhao Z. The influence of extraction on the stability of implanted titanium microscrews: a biomechanical and histomorphometric study. Int J Oral Maxillofac Implants 2009; 24(2): 267-74.

6. Gulsahi A. Bone quality assessment for dental implants: INTECH Open Access Publisher; 2011.

7. Paskalev M, Krastev S, Filipov J. Changes in some serum bone markers after experimental fracture and intera medullary osteosynthesis in dogs. Trakia J Sci 2005; 3(5): 46-50.

8. Kini $U$ and Nandeesh BN. Physiology of Bone Formation, Remodeling, and Metabolism. Radionuclide and Hybrid Bone Imaging. Springer-Verlag Berlin Heidelberg 2012; Page 32.

9. Kumar R. Tumor-induced osteomalacia and the regulation of phosphate homeostasis. Bone 2000; 27(3): 333-8.

10. Manan NA, Mohamed N, Shuid AN. Effects of low-dose versus high-dose $y$-Tocotrienol on the bone cells exposed to the hydrogen peroxide-induced oxidative stress and apoptosis. Evidence-Based Complementary and Alternative Medicine 2012; 680834.
11. Soelaiman IN, Das $S$, Shuid AN, Mo $H$, Mohamed N. Use of Medicinal Plants and Natural Products for Treatment of Osteoporosis and Its Complications. Evidence-Based Complementary and Alternative Medicine 2013; 764701.

12. Topcuoglu T, Bicakci AA, Avunduk MC, Sahin Inan ZD. Evaluation of the effects of different surface configurations on stability of miniscrews. Scientific World Journal. 2013; 2013: 396091.

13. Folwarczna J., Zych M., Trzeciak, H. Effects of curcumin on the skeletal system in rats. Pharmacol Rep 2010; 62(5): 900-09.

14. Kim W K, Ke K, Sul O J, Kim HJ, Kim SH, Lee $\mathrm{MH}$ et al. Curcumin protects against ovariectomyinduced bone loss and decreases osteoclastogenesis. J Cell Biochem 2011; 112(11): 3159-66.

15. Cho D., Jung H., Kim K., Jeon Y., Sung J., Hwang J. Therapeutic advantages of treatment of high-dose curcumin in the ovariectomized rat. J Korean Neurosurg Soc 2013; 54(6): 461-6.

16. Ali B, Blunden G. Pharmacological and toxicological properties of Nigella sativa. Phytother Res 2003; 17(4): 299-305.

17. Ozbek H., Ozturk M., Ozturk A., Cyelan E., Yener Z. Determination of Lethal Doses of Volatile and Fixed Oils of Several Plants. Eastern Journal of Medicine 2014; 9(1):04-06.

18. Potu B., Rao M., Nampurath G., Chamallamudi M., Nayak S., Thomas H. Anti-osteoporotic activity of the petroleum ether extract of Cissus quadrangularis Linn. in ovariectomized Wistar rats. Chang Gung Med J 2010; 33(3): 252-7.

19. Banu J., Varela E., Bahadur A., Soomro R., Kazi N., Fernandes G. Inhibition of Bone Loss by Cissus quadrangularis in Mice: A Preliminary Report. J Osteoporos 2012; 101206 (10): 21.

20. Hayatullina Z., Muhammad N., Mohamed N., Soelaiman I. Virgin coconut oil supplementation prevents bone loss in osteoporosis rat model. Evid Based Complement Alternat Med 2012; 237236: 16.

21. Soelaiman I., Das S., Shuid A., Mo H., Mohamed N. Use of Medicinal Plants and Natural Products for Treatment of Osteoporosis and Its Complications. Evidence-Based Complementary and Alternative Medicine 2013; 764701.

22. Morris HF, Winkler S, Ochi S. The ankylosed endoessous dental implant: Assessment of stability up to 18 months with the periotest. J Oral Implantology 2000; XXVI (4): 291-9.

23. Rickard DJ, Sullivan TA, Shenker BJ, Leboy PS, Kazhdan I. Induction of rapid osteoblast differentiation in rat bone marrow stromal cell cultures by dexamethasone and BMP-2. DevBiol 1994; 161: 218-28.

24. Cheng SL, Yang YW, Rifas L, Zhang SF, Avioli LV. Differentiation of human bone marrow osteogenic stromal cells in vitro: induction of the osteoblast phenotype by dexamethasone. Endocrinology 1994; 134: 277-86. 
25. Wozney JM. The potential role of bone morphogenetic proteins in periodontal reconstruction. I Period 1995; 66: 506-10.

26. Bennett CN, Longo KA, Wright WS. Regulation of osteoblastogenesis and bone mass by Wht $10 \mathrm{~b}$. ProcNatlAcadSci USA 2005; 102: 3324-3329.

27. Rucci N. Molecular biology of bone remodeling: Mini-review. Clinical Cases in Mineral and Bone Metabolism 2008; 5(1): 49-56.

28. Komnenou A, Karayannopoulou M, Polizopoulou ZS, Constantinidis TC, Dessiris A. Correlation of serum alkaline phosphatase activity with the healing process of long bone fractures in dogs. Vet Clin Pathol 2005; 34(1): 35-8.

29. Kini U, Nandeesh BN. Physiology of Bone Formation, Remodeling, and Metabolism. Radionuclide and Hybrid Bone Imaging, Springer-Verlag Berlin Heidelberg 2012; 40.

30. Shapiro R, Heaney RP. Co-dependence of calcium and phosphorus for growth and bone development under conditions of varying deficiency. Bone 2003; 32: 532-40.

31. Cohen J, Maletskos CJ, Marshall JH, Williams JB. Radioactive Calcium tracer studies in bone grafts. J bone \& Joint surgery 1957; 39-A(3): 561-77.

32. Deka DK, Lahon LC, Saikia J, Mukit A. Effect of Cissus Quadrangularis in accelerating healing process of experimentally fractured radius-ulna of dog: A preliminary study. Indian J Pharmacology 1994; 26: 44-45.

33. Abdel-Sater KA, Mansour $\mathrm{H}$. Bone biomarkers of ovariectomised rats after leptin therapy. BratislLekListy 2013; 114 (6): 303-07.

34. Yang M, Wanga T, Yanb P, Chua L, Yua J, Gaoa et al.. Curcumin improves bone microarchitecture and enhances mineral density in APP/PS1 transgenic mice. Phytomedicine 2011; 18: 205-13.

35. Moon HJ, Ko WK, Han SW, Kim DS, Hwang YS, Park HK et al. Antioxidants, like coenzyme Q10, selenite, and curcumin, inhibited osteoclast differentiation by suppressing reactive oxygen species generation. BiochemBiophys Res Commun 2012; 418(2): 247-53.

36. Hussan F, Ibraheem NG,1 Kamarudin TA, Shuid AN, Soelaiman IN, Othman F. Curcumin Protects against Ovariectomy-Induced Bone Changes in Rat Model. Evidence-Based Complementary and Alternative Medicine 2012; Article ID 174916, 7 pages.

37. Cho D, Jung H, Kim K, Jeon $Y$, Sung J, Hwang J. Therapeutic Advantages of Treatment of High-Dose Curcumin in the Ovariectomized Rat. J Korean Neurosurg Soc 2013; 54: 461-6. 